\section{IDDAH DAN MASALAHNYA PERSPEKTIF PARA MUFASSIR}

\section{Ahmad Darbi. B}

Fakultas Syari'ah dan Ilmu Hukum UIN Suska Riau

\section{Abstract}

Masa iddah adalah masa tunggu bagi seorang perempuan yang dicerai oleh suaminya. Ia tidak boleh melakukan pernikahan dengan laki-laki lain. Bagi laki-laki yng menceraikan masa tunggu tersebut merupakan batas maksimal untuk rujuk kembali apabila talaknya raja'i. Para ulama berbeda pendapat dalam penentuan masa iddah tersebut. Demikian pula, mereka tidak sepakat, tentang kewajiban memberi nafkah untuk perempuan yang telah di talak tiga.

\section{Keywords : Iddah, Wajib, Ijtihad Ulama.}

\section{Pendahuluan}

Masa iddah adalah masa tunggu bagi seorang perempuan yang dicerai oleh suaminya. Tidak boleh melakukan pernikahan dengan laki-laki lain, bagi laki-laki yang menceraikan masa tunggu tersebut merupakan batas maksimal untuk rujuk kembali apabila talaknya raj'i. Iddah dari kata a'dad, artinya menghitung, maksudnya perempuan (isteri) menghitung hari-harinya dan masa bersih nya. Iddah dalam istilah agama menjadi nama bagi masa lamanya perempuan (isteri) menunggu dan tidak boleh kawin setelah kematian suaminya, atau cerai dari suaminya. ${ }^{1}$

Iddah ini sudah di kenal sejak zaman jahiliah. Mereka hampir tidak pernah meninggalkan kebiasaan iddah. Tatkala Islam datang kebiasaan tersebut diakui dan dijalankan terus, karena ada beberapa hikmah padanya. Para ulama bersepakat bahwa iddah itu wajib

${ }^{1}$ Lihat, Sayyid Sabiq, Figh al-Sunah, alih bahasa oleh Mahyuddin Syaf, (Bandung: Al-Ma’arif, 1996), Cet. ke 10, jilid 8,. hlm.139. hukumnya. Di antara hikmah iddah adalah : untuk mengetahui bersihnya rahim seorang perempuan, sehingga tidak tercampur antara keturunan seseorang dengan yang lain, memberi kesempatan kepada suami istri yang bercerai untuk kembali kepada kehidupan suami isteri. Dan menjunjung tinggi masalah perkawinan, memberi tempo untuk berpikir panjang (memikirkan secara matang). ${ }^{2}$

Teks ayat-ayat al-qur'an dan hadits Nabi telah menjelaskan berkaitan dengan masalah iddah tersebut. Para mufassir juga telah membahas ayat-ayat dan hadist-hadist tersebut. Dalam bahasan para mufassir tersebut di temukan berbedaan-perbedaan pendapat.

Dalam makalah ini penulis berusaha menelusuri pendapat mufassir tersebut dan mencermati alur pemikiran, dalil yang mereka gunakan dan metode istinbath yang mereka pakai.

\section{Macam-Macam Iddah}

Berdasarkan teks ayat-ayat al-Quran, iddah ada beberapa macam, yaitu : Iddah isteri yang berhaid, yaitu tiga kali haid, Iddah isteri yang mati haid, yaitu tiga bulan, Iddah isteri yang kematian suami, yaitu empat bulan sepuluh hari, dan Iddah isteri hamil, yaitu sampai melahirkan. ${ }^{3}$

\section{Iddah Isteri yang Berhaid}

Iddah Isteri yang masih berhaid bila dicerai suaminya. ${ }^{4}$ Isteri yang ditalak tersebut, ada kalanya sudah disetubuhi dan adakalanya belum disetubuhi.

${ }^{2}$ Lihat Wahbah al-Zuhailiy, Al-Tafsir al-Munir fi al-Aqidah wa al-Syari'ah wa alManhaj, (Beirut: Dar al-Fikr al-Mu'ashir, 1991), Cet. ke 1, jilid 2,. hlm. 370. Lihat juga Muhammad Ali al-Savis, Tafsir Ayat al-Abkam, (t.t., t.p., t.th.), hlm.137.

${ }^{3}$ Lihat, Sayyid Sabiq, Fiqh al-Sunah,. hlm. 141.

${ }^{4}$ Sebab-sebab terjadinya talak tersebut ialah: Talak, Khulu', Zhihar, Li'an, Ila', Fasakh dan Murtad., Talak, melepaskan ikatan perkawinan atau bebannya hubungan perkawinan. Khulu' artinya: Isteri memisahkan diri dari suaminya dengan ganti rugi kepada suaminya., Lihat lebih jelas Sayyid Sabiq, Figh al-Sunah, hlm. 9 dan 95. Zhihar, dari kata zhahr, artinya punggung, maksudnya suam berkata kepada isterinya engkau dengan aku seperti punggung ibuku. Menurut Ibnu 
1. Iddah Isteri yang Belum Disetubuhi:

Isteri yang ditalak oleh suaminya, tapi belum pernah di setubuhi, maka ia tidak punya iddah. Hal itu berdasarkan firman Allah Q.S alAhzab ayat 49:

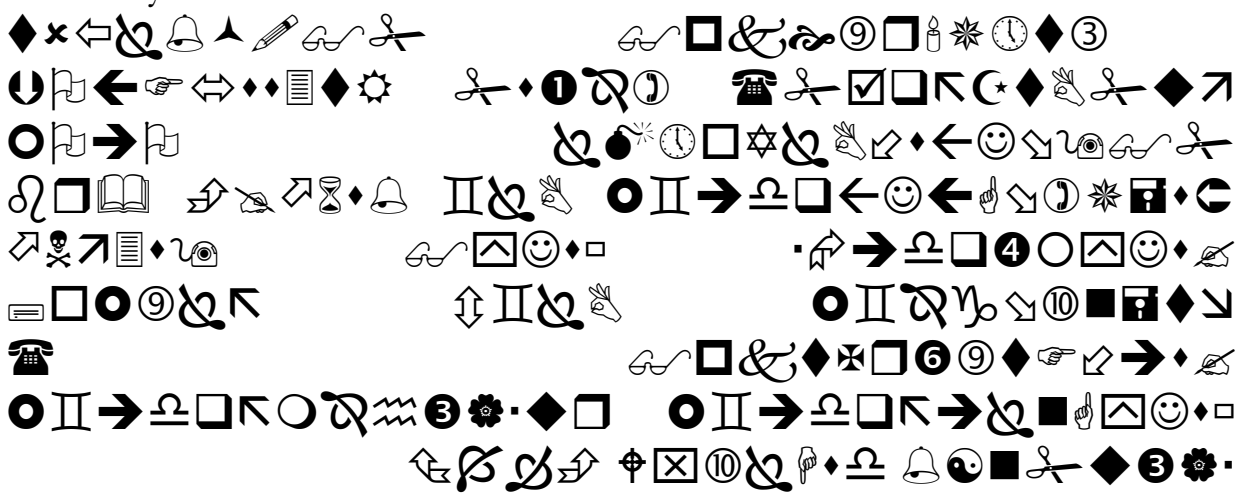

Artinya : Hai orang-orang yang beriman, apabila kamu menikahi perempuan- perempuan yang beriman, Kemudian kamu ceraikan mereka sebelum kamu mencampurinya Maka sekali-sekali tidak wajib atas mereka 'iddah bagimu yang kamu minta menyempurnakannya. Maka berilah mereka

Qayyim, pada zaman jahiliyah Zhihar di pandang sebagai talak, lalu dibatalkan oleh Islam serta tetap dipandang tidak berlaku. Selain itu bahwa Aus bin Shamid pernah menzhihar dengan maksud talak. Tetapi yang diberlakukan tetap zbihamya, bukan talak. Zhihar ini sudah jelas hukumnya. Karena itu tidak boleh zhihar yang sudah dibatalkan hukumnya oleh Allah. Isteri yang dizhihar tetap sebagai isteri akan tetapi haram digauli sebelum membayar kifarat. Li'an, berarti "menjauhkan" suami ister yang bermu'alanah. Disebut demikian karena sesudah li'an akan mendapat dosa dan dijauhkan satu sama lain selama-lamanya. Dan jika salah satunya ternyata dusta, maka dialah yang dilaknat oleh Allah. Ila' ialah suami bersumpah tidak akan menggauli isterinya. Apabila lebih dari 4 bulan maka jatuhlah talak., lihat lebih jelas Muhammad Ali al-Savis, Tafsir Ayat Abkam, juz I, hlm.134-137. Fasakh berarti batalnya aqad nikah. Memfasakhkan berarti membatalkan dan melepaskan ikatan perkawinan antara suami isteri. Fasakh bisa terjadi karena syarat-syarat yang tidak terpenuhi pada akad nikah atau karena hal-hal yang datang kemudian yang membatalkan kelangsungannya perkawinan. Lihat lebih jelas Fiqih sunah, hlm. 124. mut'ah dan lepaskanlah mereka itu dengan cara yang sebaik- baiknya.

Menurut al-Shabuny dalam tafsirnya, bahwa wanita yang ditalak suaminya sebelum dukbul tidak wajib iddah. Pendapat ini adalah ijma' para Ulama. ${ }^{5}$

Jika isteri yang belum pernah disetubuhi ditinggal wafat suaminya, maka ia harus beriddah seperti iddahnya orang yang sudah disetubuhi. Berdasarkan firman Allah Q.S al-Baqarah ayat 234

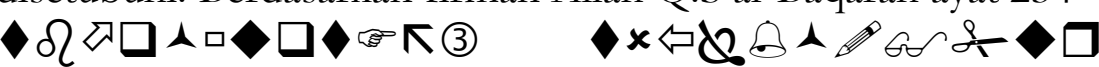

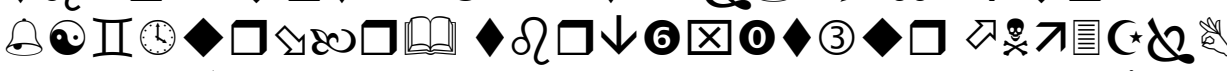

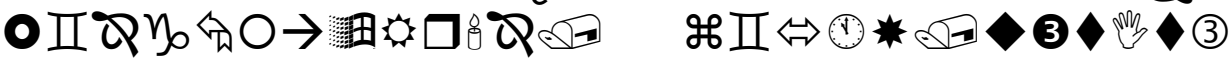
2०2K\&\&企 $\square$ 回四

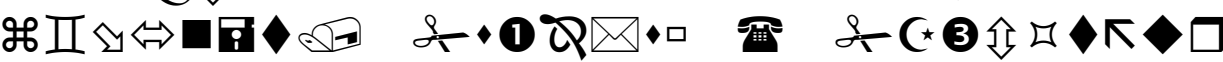

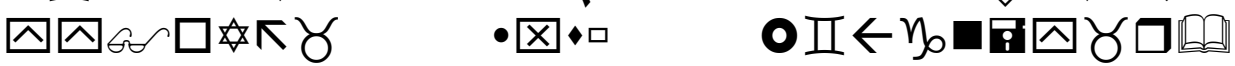

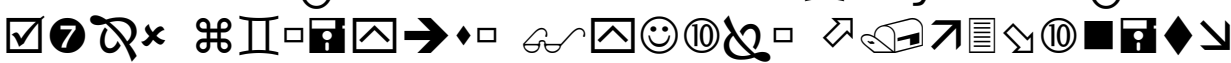

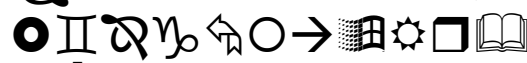

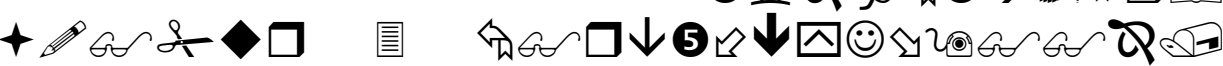

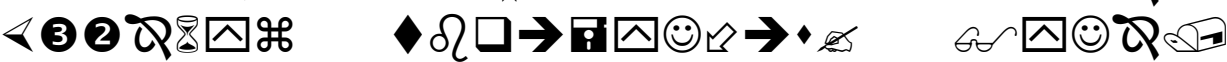

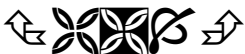

Artinya : Orang-orang yang meninggal dunia di antaramu dengan meninggalkan isteri-isteri (hendaklah para isteri itu) menangguhkan dirinya (ber'iddah) empat bulan sepuluh hari. Kemudian apabila Telah habis 'iddahnya, Maka tiada dosa bagimu (para wali) membiarkan mereka berbuat terhadap diri mereka menurut yang patut. Allah mengetahui apa yang kamu perbuat.

Isteri yang di tinggal wafat suaminya wajib iddah, sekalipun belum pernah disetubuhi. Hal ini adalah untuk menyempurnakan dan menghargai hak suami yang wafat tersebut.

\section{Iddah Isteri yang Telah Disetubuhi:}

${ }^{5}$ Muhammad Ali al-Shabuny, Rawai'u al-Bayan Tafsir Ayat al-Ahkam min alQuran, (Makkah al-Mukarramah, t.p., t.th.), Jilid 2, hlm. 296. 
Isteri yang sudah pernah disetubuhi adakalanya masih berhaid atau sudah mati haid (monopouse). Iddah perempuan yang berhaid: iddahnya adalah tiga kali quru', sebagaimana firman Allah Q.S alBaqarah ayat 228:

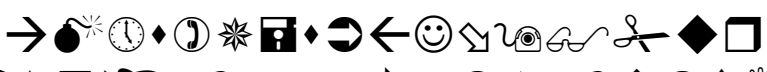

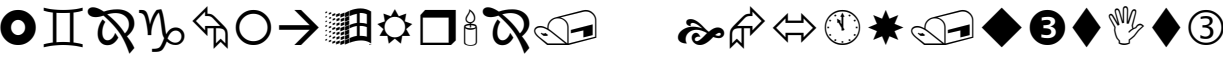

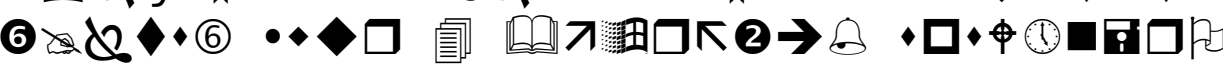
Gr है HII

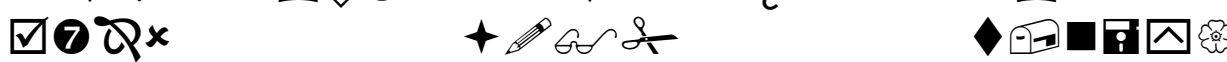
-II

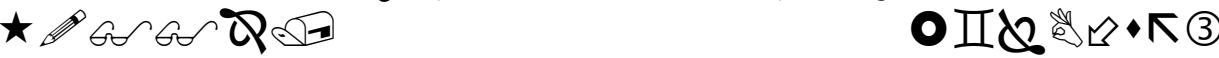

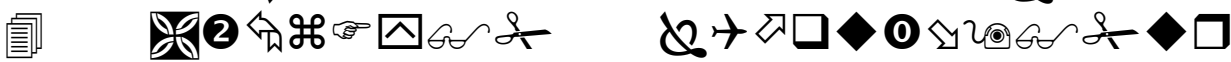

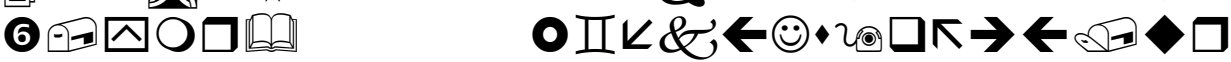

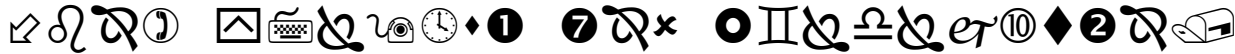

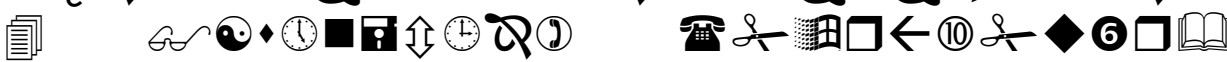

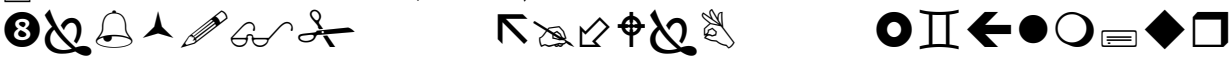

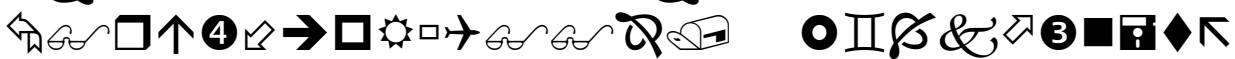

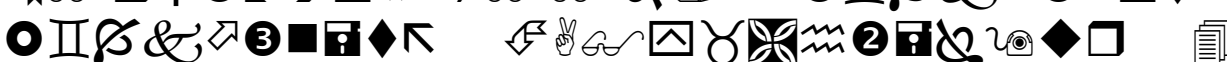

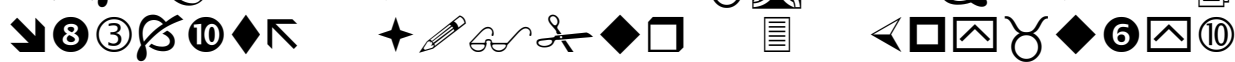

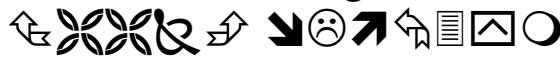

Artinya : Wanita-wanita yang ditalak handaklah menahan diri (menunggu) tiga kali quru'. tidak boleh mereka menyembunyikan apa yang diciptakan Allah dalam rahimnya, jika mereka beriman kepada Allah dan hari akhirat. dan suami-suaminya berhak merujukinya dalam masa menanti itu, jika mereka (para suami) menghendaki ishlah. dan para wanita mempunyai hak yang seimbang dengan kewajibannya menurut cara yang ma'ruf. akan tetapi para suami, mempunyai satu tingkatan kelebihan daripada isterinya. dan Allah Maha Perkasa lagi Maha Bijaksana.

Untuk memahami ayat (al-Baqarah 228) para Fuqaba meneliti apakah ayat tersebut mempunyai asbab al-Nuzul. Memahami asbab al-
Nu₹ul ayat merupakan bagian dari kaidah ushul yang menyatakan pemahaman ayat dengan asbab al-Nuzul nya. Asbab al-Nuzul dari ayat tersebut adalah sebagai berikut:

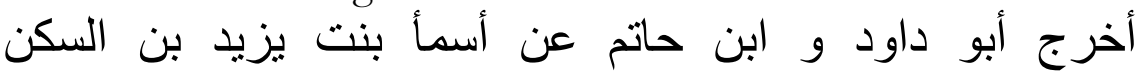

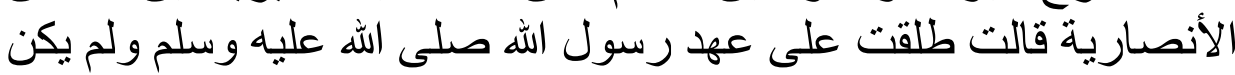

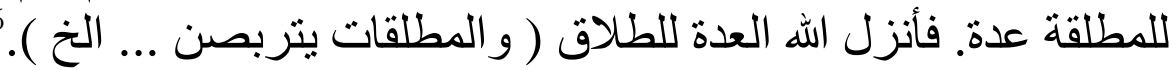

Artinya: Abu Daud mengeluarkan dari Ibnu Abi Hatim dari Asma' binti Yazid bin al-Sakan al-Anshariyah, Dia menyatakan aku telah di talak pada masa Rasulullah dan tidak ada iddah maka turunlah ayat tersebut.

Para ulama memahami ayat tersebut bahwa para wanita yang dicerai (talak) oleh suami mereka wajib bagi wanita tersebut beriddah (massa tunggu) selama tiga quru'.

Kalimat " adalah Khabariyah dengan makna al-amr " ليتربصن،. Dengan pengertian al-amr tersebut, maka ayat tersebut mewajibkan para wanita yang dicerai suami mereka wajib beriddah.7

Para ulama tidak berbeda pendapat tentang wajib iddah tersebut, akan tetapi mereka tidak sepakat tentang penghitungan massa iddah tersebut. Perbedaan tersebut di sebabkan oleh lafaz " قروء yang terdapat dalam teks ayat tersebut.

Lafaz" " قروء " dari segi I'rabnya adalah mudhaf ilaih, sedangkan sebagai maf'ul bih atau ₹haraf. Dengan pengertian selama tiga quru' ( ( مدة ثلاثة أقراء ). Quru' jama' kastrah jama' qillah nya adalah aqra' ( أقراء). Mengidhafah kan 'adad al-Qalil kepada jama' al-qillah lebih utama, ketimbang mengidhafabkan nya kepada jama' katsrah. Namun di sini diidhafabkan kepada jama' katsrah. Boleh jadi, kata Wahbah Zuhairi

${ }^{6}$ Lihat Jaluddin Abd al-Rahman bin Abi Bakar al-Suyuthi, Lubab al-Nuqul fi Asbab al-Nuzul, (Riyadh: Maktabah al-Riyadh al-Haditsah, t.th.). Cet. ke 2, hlm. 36.

${ }^{7}$ Lihat Wahbah, Al-Munir, jilid 2 hlm. 318., Abu Zahrah, hlm. 177., Ahmad al-Hasyimiy, Jawahir al-Balaghah fi al-Ma'any wa al-Bayan wa al-Badi, (Indonesia: Maktabah Dar al-Ihya' Al-Kutub al-Arabiyah, t.th)., hlm. 294., Lihat, M. Ali Sayis, Tafsir Ayat Abkam, hlm. 138. 
dalam tafsirnya, karena itulah yang banyak / sering digunakan oleh orang Arab. ${ }^{8}$

Quru' dari segi arti, mempunyai lebih dari satu arti. Inilah yang di sebut lafaz Musytarak. Quru' diartikan dengan suci dan diartikan dengan haid. Arti asal Quru' adalah al-ijtima' (berkumpul). Yakni berkumpulnya darah dalam badan. Quru' diartikan dengan haid karena berkumpulnya darah dalam rahim. Terkadang kata Quru' juga dipakai untuk waktu, datangnya dan pergi sudah mempunyai periode-periode tertentu. Haid, datang dan perginya mempunyai siklus tertentu, maka orang Arab menyebutnya dengan Quru'?

Dalam hadist kata Quru' di artikan dengan haid, sabda Rasulullah saw. Kepada Fatimah binti Abi Habisy. Oleh karena itu Hanafiyah dan Hanabilah berpendapat bahwa yang dimaksud dengan Quru' adalah haid. Sedangkan Malikiyah dan Syafiiyah mengartikan dengan suci. ${ }^{10}$

Dengan demikian, maka iddah wanita yang dicerai oleh suaminya wanita tersebut tidak hamil, tidak monopause atau masih belum dewasa / belum berhaid atau dewasa tapi memang tidak berhaid, atau wanita yang belum pernah disetubuhi oleh suaminya, maka iddahnya tiga kali haid. Pendapat ini, adalah pendapat Hanafiyah, Hanabilah, alTsauri, al-Auza'i, Ibnu Abi Laila. Dari kalangan sahabat antara lain Ali r.a Umar bin Khatab r.a Ibnu Mas'ud dan Ibnu Musa al-Asy'ari r.a.

Hal ini dikuatkan oleh Ibnu Qayyim. Kata beliau: Kata qur'un hanya digunakan oleh agama dengan arti haid. Tidak satu ayat pun pernah digunakan kata qur'un dengan arti bersih dari haid. Karena itu maka memahamkan kata qur'un dalam ayat di atas menurut yang popular dari titah agama adalah lebih baik, bahkan haruslah begitu.

Karena Rasulullah telah bersabda kepada seorang perempuan yang berhaid, "tinggalkanlah shalatmu selama quru'mu (haidmu)".

Rasulullah s.a.w. adalah juru penerangan dari Allah dan dengan bahasa arab pula al-Quran diwahyukan. Jika di dalam al-Quran terdapat satu

${ }^{8}$ Lihat Wahbah, Al-Munir..., hlm. 318.

${ }^{9}$ Wahbah, Al-Munir..., hlm. 318., lihat, al-Shabuni, Rawai'u..., hlm. 318.

${ }^{10}$ Lihat Al-Shabuni, Rawai'u..., hlm. 318. kata yang punya beberapa arti maka semua arti tersebut wajib digunakan, selama tidak ada keterangan yang menentukan untuk salah satu arti saja. Dan dengan demikian ia menjadi bahasa Al-Quran yang diwahyukan kepada kita sekalipun kata tersebut dalam bahasa lain punya arti lain.

Jika sudah jelas arti kata quru' dalam agama dipakai dengan arti haid, maka jelaslah bahwa itulah memang arti yang sesungguhnya. Dengan demikian maka hanya itulah arti kata quru' tersebut. Dan hal ini juga ditunjukkan oleh susunan kalimat ayat tersebut yang berbunyi:

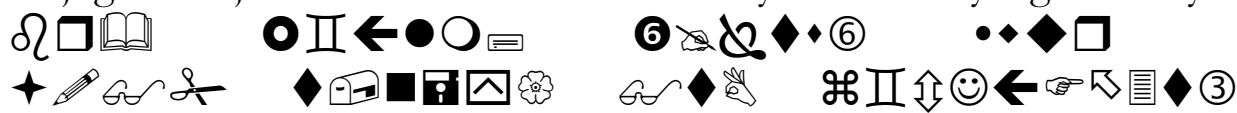

Demikianlah ayat ini mengenai perempuan haid dan hamil. Demikianlah pendapat kebanyakan ahli tafsir. Terwujudnya janin dalam rahim hanyalah terjadi selama masih berhaid ${ }^{11}$.

Sementara yang mengartikan quru' dengan suci, berarti iddahnya tiga kali suci. Pendapat ini adalah pendapat Malikiyah, Syafiiyah, Abu Tsur. Dari kalangan sahabat antara lain Ibnu Umar Zaid bin Tsabit dan Aisyah r.a.

Argument yang dikemukakan oleh kelompok ini:

a. Quru' menurut bahasa, perpindahan dari periode suci kepada haid, bukan keluar dari periode haid kepada suci. Perpindahan dari periode suci kepada haid memberi isyarat bahwa rahim suci. Karena seseorang yang hamil biasanya tidak akan berhaid

b. Kata quru' berbentuk muannats, ini menunjukkan bahwa yang dibilang (ma'dud) adalah muzakar, bukan muannats, yaitu al-Thubr bukan al-haidh (muannats)

c. Firman Allah dalam surat al-Talak ayat 1 


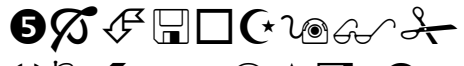

(1) 的 $<\backsim($ ()

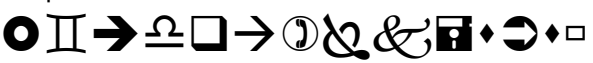

융 \& $\square$ (1)

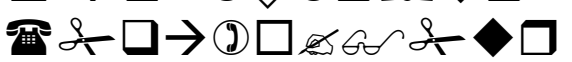

$\bullet$

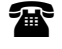

$\Delta \underset{x}{2} \rightarrow$

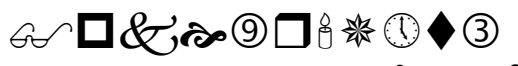

से (1) का (1)

$\Delta \pi$ ar OD) ( 20an

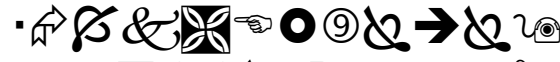

ताएव है

$\measuredangle \wedge(2 \unlhd(3) \cdot(6)$

\section{$\bullet \bullet \square$}

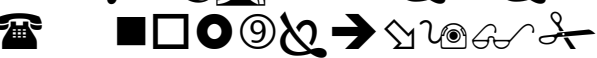

* $\theta 0<10$ ar

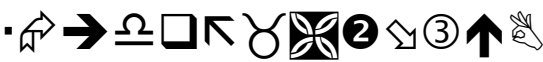

- II Q

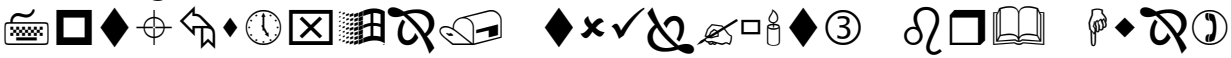

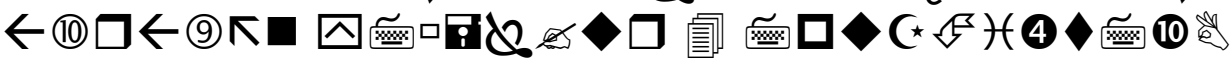

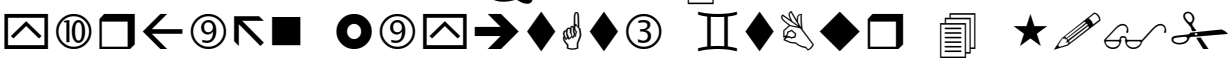

- 囯 (1)

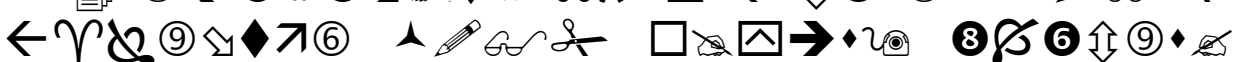

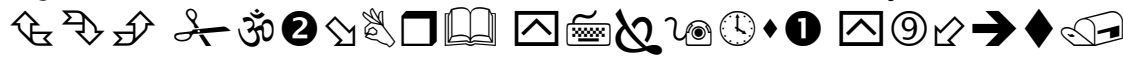

Artinya : Hai nabi, apabila kamu menceraikan isteri-isterimu, maka hendaklah kamu ceraikan mereka pada waktu mereka dapat (menghadapi) iddahnya (yang wajar) dan hitunglah waktu iddah itu serta bertakwalah kepada Allah Tuhanmu. janganlah kamu keluarkan mereka dari rumah mereka dan janganlah mereka (diizinkan) ke luar kecuali mereka mengerjakan perbuatan keji yang terang. Itulah hukumhukum Allah, maka Sesungguhnya dia Telah berbuat zalim terhadap dirinya sendiri. Kamu tidak mengetahui barangkali Allah mengadakan sesudah itu sesuatu hal yang baru.

Talak untuk iddah yaitu selama masa suci. Talak tersebut disebut dengan talak sunniy Sedangkan talak pada masa haid adalah talak bid'iy dan Talak tersebut dilarang. ${ }^{12}$

Adapun iddah menurut Umar, Ali, Ibnu Mas'ud, Hanafiyah dan Hanabilah menurut salah satu riwayat yang paling shahih dari Ahmad, adalah tiga kali haid. Mereka meruju' kepada perhitungan iddah hamba 138.

${ }^{12}$ Lihat Wahbah, Al-Munir..., hlm. 323., lihat juga M. Ali Sayis, Tafsir... hlm. sahaya yakni dua kali haid. Perhitungan iddah hamba sahaya dua kali haid ini kesepakatan ulama, berdasarkan kepada sabda Nabi Saw:

$$
\text { طلاقة الأمة تطليقاتان و عدتهن حيضنان. }
$$

Artinya: "Talak hamba sahaya adalah dua kali talak dan iddahnya dua kali haid"

Mereka menganalogikan perhitungan iddah seorang wanita yang merdeka dengan perhitungan iddah hamba sahaya. ${ }^{13}$ Dengan pengertian perhitungan masa iddah hamba sahaya, dihitung dengan dua kali haid. Untuk wanita yang merdeka mereka hitung pula dengan masa haid sehingga iddah wanita yang merdeka tiga kali haid. ${ }^{14}$

Apabila seseorang menceraikan isterinya di pertengahan masa suci, maka menurut pendapat yang pertama iddahnya sampai dengan datangnya haid yang ketiga. Sedangkan menurut pendapat yang kedua, iddahnya sampai dengan habisnya haid yang ketiga. ${ }^{15}$

Para ulama telah menghitung jumlah hari iddah tersebut. Menurut Abu Hanifah minimal 60 hari. ${ }^{16}$ Menurut Malikiyah alAqra'/at-Thahar satu bulan sehari; seorang suami mentalak isteri di awal bulan dalam keadaan suci, kemudian dia haid, minimal haid bagi mereka satu hari atau setengah hari, kemudian suci 15 hari, kemudian haid pada malam yang ke 16, dan haid sebelum fajar. ${ }^{17}$ Menurut Syafiiyah minimalnya 32 hari, tambah dua lahz̧hah sedangkan menurut Hanabilah 29 hari. ${ }^{18}$

Ulama Fiqh berbeda pendapat tentang hukum bagi wanita yang sedang dalam masa iddah, apakah seperti hukum isteri atau tidak. Menurut Hanafiyah, bahwa wanita tersebut seperti isteri, maka tidak haram bagi melakukan istimta' dan mubasyarah. Hukum suami isteri

${ }^{13}$ Lihat al-Munir, hlm. 323., lihat juga, M. Ali Sayis, hlm. 138.

${ }^{14}$ Lihat al-Munir, hlm. 323., lihat juga, M. Ali Sayis, hlm. 138.

${ }^{15}$ Lihat, al-Munir, hlm. 324.

${ }^{16}$ Perhitungannya, mengambil pertengahan masa haid yaitu 5 hari, berarti $3 \times 5=15$, masa suci 45 hari, totalnya 60 hari.

${ }^{17}$ Lihat, al-Munir, hlm. 324.

${ }^{18}$ Lihat, al-Munir, hlm. 324. 
tidak hilang sedikit pun. ${ }^{19}$ Malikiyah dan Syafiiyah berpendapat, hukumnya bukan sebagai hukum isteri, maka haram melakukan istimta sebelum ruju'. Bahkan memandangnya juga haram sekalipun tanpa syahwat, karena talak telah membatalkan akad nikah. ${ }^{20}$ Yaitu akad yang menghalalkan seseorang laki bersenang-senang dengan seorang perempuan. Akad merupakan penghalalan mengambil manfaat dari seorang wanita.

Menurut Wahbah Zuhaily, penyebab perbedaaan pendapat mereka tersebut adalah kalimat " وبعولتهن "Allah SWT dalam ayat tersebut menyebut laki-laki yang mentalak sebagai bu'ulah (suami). Menurut kelompok pertama (Hanafiyah) tetap sebagai suami dan boleh melakukan istimta' dan jima'. Sedangkan faedah talak hanya mengurangi bilangan talak bila ikatan suami isteri berlanjut. ${ }^{21}$

Menurut kelompok kedua (Malikiyah dan Syafi'iyah), kata tersebut merupakan ungkapan untuk sebelum terjadi talak. ${ }^{22}$ Dalam ilmu balaghah inilah yang disebut majaz mursal. ${ }^{23}$ Sehingga pengertian kalimat tersebut suami mereka (sebelum terjadi talak) lebih berhak.

\section{Iddah Isteri yang Dicerai Wafat Suaminya}

Wanita yang dicerai wafat suaminya, iddahnya empat bulan sepuluh hari. Hal tersebut berdasarkan QS. al-Baqarah 234 yaitu:

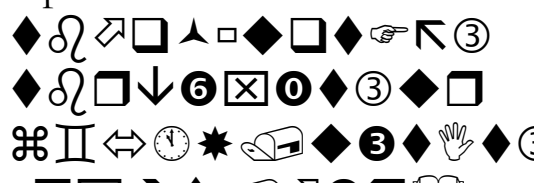

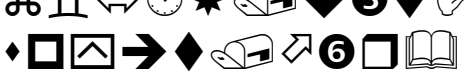

${ }^{19}$ Lihat, al-Munir, hlm. 324.

${ }^{20}$ Lihat al-Munir, hlm. 324.

${ }^{21}$ Lihat, al-Munir, hlm. 324.

22Lihat, al-Munir, hlm. 324.

${ }^{23} \mathrm{Ahmad}$ al-Hasyimiy, Jawabir al-Balaghah fi al-Ma'any wa al-Bayan wa al-Badi, (Indonesia: Maktabah Dar al-Ihya' Al-Kutub al-Arabiyah, t.th.)., hlm. 294., lihat juga Muhammad Abu Zahrah, Usbul al-Figh, (t.t: Dar al-Fikr al-Arabiy, 1954). hlm. 152

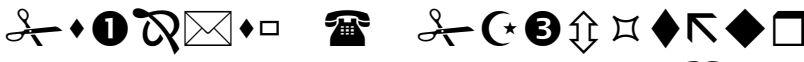

- $\mathrm{x} \cdot \mathrm{a}$

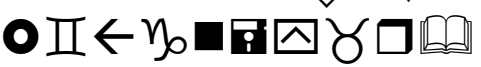

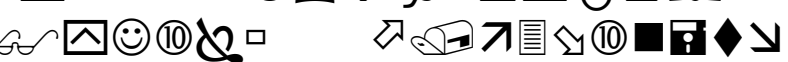

- II Q

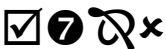

202K\&占* $\square$ 回

HII $₫ \Leftrightarrow \square$ 穴

$\triangle \otimes G \square \bowtie \kappa \gamma$

HII

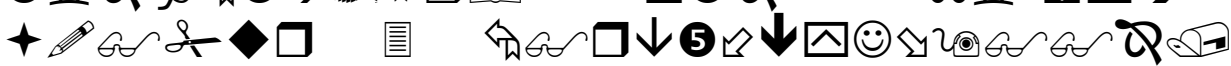

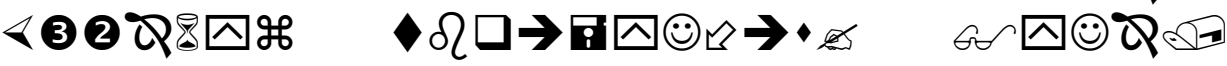

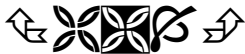

Artinya : Orang-orang yang meninggal dunia di antaramu dengan meninggalkan isteri-isteri (hendaklah para isteri itu) menangguhkan dirinya (ber'iddah) empat bulan sepuluh hari. Kemudian apabila Telah habis 'iddahnya, Maka tiada dosa bagimu (para wali) membiarkan mereka berbuat terhadap diri mereka menurut yang patut. Allah mengetahui apa yang kamu perbuat.

Wahbah Zuhaili dalam menafsirkan ayat tersebut, menyebutkan bahwa wanita yang dicerai wafat suaminya dan tidak dalam keadaan hamil iddahnya empat bulan sepuluh hari. Sedangkan wanita dalam keadaan hamil iddahnya sampai melahirkan sekalipun satu jam setelah suaminya wafat. Dan tidak ada perbedaan antara wanita/isteri yang kecil atau yang sudah tua, yang telah digauli atau belum digauli. ${ }^{24}$ Iddah wanita yang dicerai wafat suaminya dijelaskan lagi dalam surat Al-Talak ayat 4 :

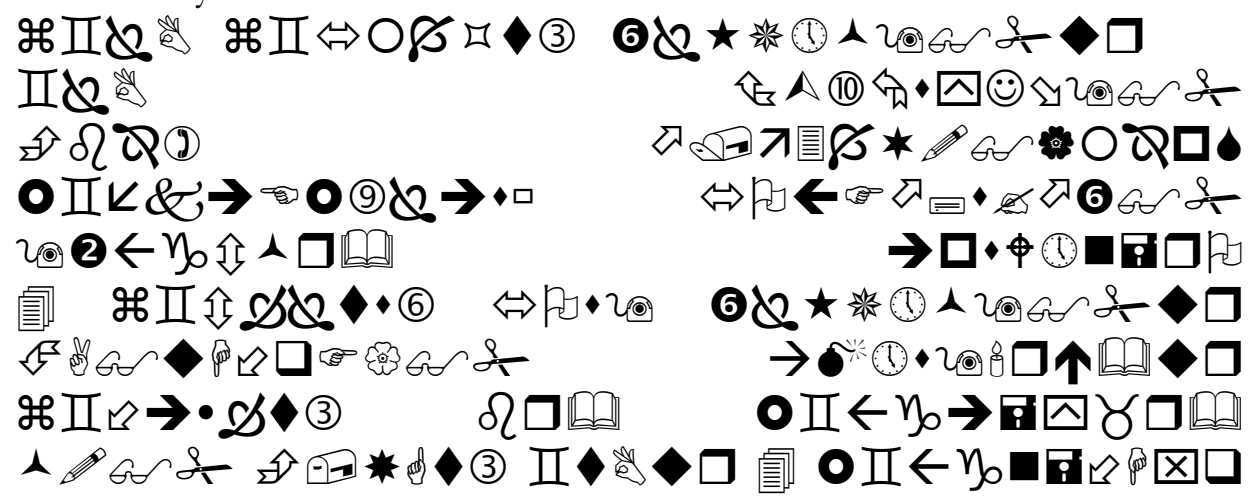

${ }^{24}$ Lihat al-Munir, hlm. 324. 
Artinya : "Dan perempuan-perempuan yang tidak haid lagi (monopause) di antara perempuan-perempuanmu jika kamu ragu-ragu (tentang masa iddahnya), Maka masa iddah mereka adalah tiga bulan; dan begitu (pula) perempuanperempuan yang tidak haid. dan perempuan-perempuan yang hamil, waktu iddah mereka itu ialah sampai mereka melahirkan kandungannya. dan barang -siapa yang bertakwa kepada Allah, niscaya Allah menjadikan baginya kemudahan dalam urusannya".

Menurut mayoritas ulama, ayat 4 surat al-Talak ini menasakhkan Q.S al-Baqarah ayat 240 namun pendapat ini tidak luput dari perdebatan para Ulama. Ayatnya adalah sebagai berikut:

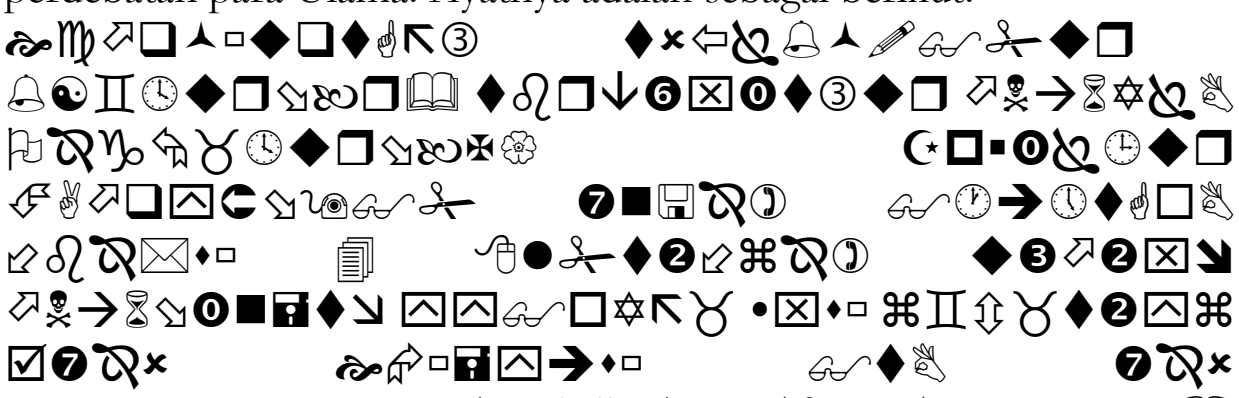

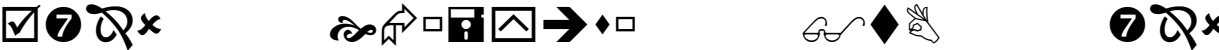

帮

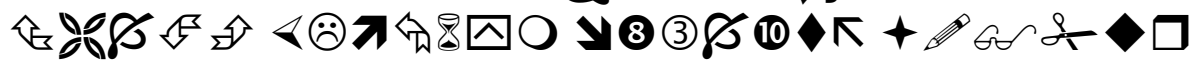

Artinya : "Dan orang-orang yang akan meninggal dunia di antara kamu dan meninggalkan isteri, hendaklah berwasiat untuk isteri-isterinya, (yaitu) diberi nafkah hingga setahun lamanya dan tidak disuruh pindah (dari rumahnya). Akan tetapi jika mereka pindah (sendiri), Maka tidak ada dosa bagimu (wali atau waris dari yang meninggal) membiarkan mereka berbuat yang ma'ruf terhadap diri mereka. Dan Allah Maha Perkasa lagi Maha Bijaksana".

Masyarakat pada permulaan Islam apabila seorang suami wafat dan meninggalkan isteri dalam keadaan hamil maka diwasiatkan agar isterinya tersebut diberi nafkah dan tempat tinggal selama setahun, selama ia tidak keluar dari rumah tersebut atau bersuami kembali. Kemudian hukum ini diganti dengan 4 bulan 10 hari, dan ayat tentang mewarisi. ${ }^{25}$ Dalam ulumul Qur'an, istilah Nasikh dan mansukh diartikan sebagai yang menghapus dan yang dihapus, artinya yang datang kemudian menghapus hukum yang sebelumnya (terdahulu). Sungguhpun Wahbah Zuhaili tidak menjelaskan tentang kedua ayat tersebut dari segi sejarahnya, namun dapat dipahami dari kalimat yang digunakan (لأن الناس كانوا فى مبداء الإسلام)

Dari kalimat tersebut menunjukkan, bahwa ayat 240 surat alBaqarah lebih dahulu turun dari pada ayat 4 surat al-Talak. Dengan demikian surat al-Talak ayat 4 menghapus hukum pada surat alBaqarah ayat $240 .{ }^{26}$ Oleh sebab itu, maka iddah bagi wanita yang dicerai wafat suaminya tidak dalam keadaaan hamil iddahnya empat bulan sepuluh hari.

Pendapat lain mengatakan ayat 240 surat al-Baqarah tersebut bukan dinasakbkan tetapi ditakbsiskan ${ }^{27}$. Dengan pengertian ayat 240 surat al-Baqarah bersifat umum, sedangkan ayat 4 surat al-Talak bersifat khusus. Yakni menyebutkan wanita yang sedang hamil iddahnya sampai melahirkan.

\section{Iddah Isteri yang Sedang Hamil Dicerai Wafat Suaminya}

Isteri yang sedang hamil dan dicerai wafat suaminya, iddahnya diperdebatkan oleh para ulama, sebagai berikut:

a. Menurut Jumhur Ulama iddahnya sampai melahirkan. Pendapat mereka ini berdasarkan kepada ayat 4 dari surat al-Talak. ${ }^{28}$ Nawawi dalam Syarah Muslim menyebutkan: Ulama dalam mazhab kami dan

${ }^{25}$ Lihat Al-Munir, hlm. 324.

${ }^{26}$ Abu Zahrah, hlm. 184, lihat juga Mana' al-Qaththan, Mabahits fi lum alQuran, (Beirut, Muassasah al-Risalah, 1990), hlm. 231.

${ }^{27}$ Muhammad bin Isma'il al-Kahlani, Subul al-Salam, (Mesir: Maktabah Syirkah Mushthafa al-Baby al-Halaby wa Awladihi, 1950), cet. ke 2, hlm.197.

${ }^{28}$ Lihat Al-Munir, hlm. 324. 
dari selainnya, mereka menyebutkan, sama ada yang dikandungnya tersebut satu orang anak atau lebih, telah sempurna bentuknya atau belum, iddah wanita tersebut habis dengan melahirkan kehamilannya, apabila bentukkanya seperti manusia sekalipun nyaris tidak dikenali. Syafi'i menambahkan, tidak habis iddahnya kalau dia melahirkan sepotong daging yang tidak berbentuk. ${ }^{29}$

b. Ali bin Abi Thalib dan Ibnu Abbas berpendapat bahwa iddah wanita yang sedang hamil dan dicerai wafat suaminya iddah adalah yang paling panjang waktunya di antara dua iddah tersebut. Dengan pengertian apabila iddah sampai melahirkan kurang dari 4 bulan 10 hari, maka iddah yang dipakai / dihitung adalah iddah empat bulan 10 hari. Akan tetapi, apabila masa iddah sampai melahirkan lebih panjang dari 4 bulan 10 hari, maka iddahnya yang dihitung adalah sampai melahirkan. Pendapat ini berdasarkan kepada al-jam'u (mengumpulkan) antara iddah wafat dan iddah wanita hamil.

Mengumpulkan (al-jum' $u$ ) kedua ayat tersebut lebih utama ketimbang mentarjibkan demikian menurut ittifaq ulama ushul, kecuali Hanifiah. Dia lebih mengutamakan "tarïh" ketimbang jam'u. 30 Pendapat di ini tertolak dengan hadis Subai'ah al-Islamiyah dalam kitab Shabih. Sesungguhnya dia telah nifas setelah suaminya wafat beberapa malam. Dia menyampaikan kepada Rasulullah hal tersebut dan menanyakan apakah dia dibolehkan untuk menikah dalam keadaan tersebut? Nabi membolehkan. Al-Zuhry mengatakan : Saya tidak melihat keburukan bahwa dia menikah ketika setelah melahirkan sungguhpun masih dalam keadaan nifas. Hanya saja, suaminya tidak boleh menghampirinya hingga isteri nya itu suci. Ini pendapat Jumhur ulama dan Imam-imam Fuqaha. ${ }^{31}$

${ }^{29}$ Ismail, Subul al-Salam, hlm.198

${ }^{30}$ Ismail, Subul al-Salam, hlm.198.

${ }^{31}$ Wahbah, Al-Munir, hlm. 372.
4. Iddah Isteri yang Tidak Berhaid dan Isteri yang Telah Mati Haid (Monopouse)

Wanita yang tidak menstruasi dan yang telah putus dari haid (monopouse), iddah nya 4 bulan 10 hari sesuai dengan firman Allah QS. al-Talak : 4

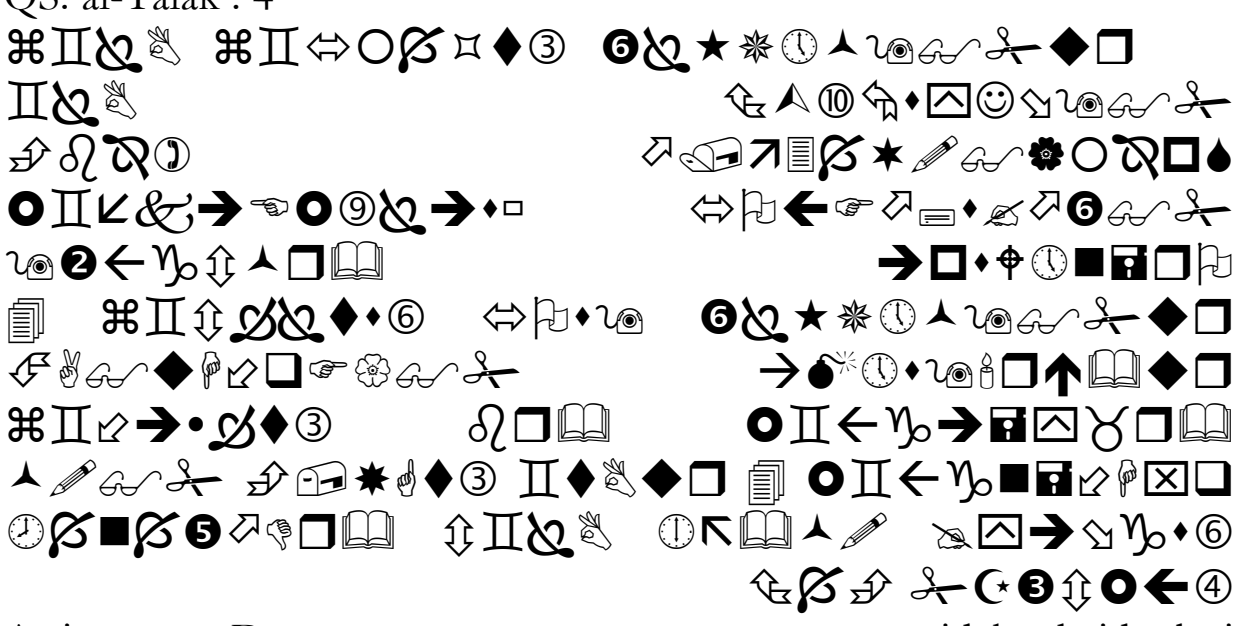

Artinya : Dan perempuan-perempuan yang tidak haid lagi (monopause) di antara perempuan-perempuanmu jika kamu ragu-ragu (tentang masa iddahnya), Maka masa iddah mereka adalah tiga bulan; dan begitu (pula) perempuanperempuan yang tidak haid. dan perempuan-perempuan yang hamil, waktu iddah mereka itu ialah sampai mereka melahirkan kandungannya. dan barang -siapa yang bertakwa kepada Allah, niscaya Allah menjadikan baginya kemudahan dalam urusannya.

Untuk memahami ayat tersebut para ulama meneliti asbab alnu₹ulnya. Ibnu Jasir Ishaq bin Rahuwaih, al-Hakim dan selain mereka mengeluarkan dari Ubay bin Ka'ab. Dia mengatakan ketika telah turun ayat surat al-Baqarah tentang iddah wanita yang di talak suaminya dan wanita yang dicerai wafat suaminya mereka, bagaimana para wanita 
yang belum disebutkan (yang kecil, yang tua dan wanita yang hamil), maka turunlah ayat 4 surat al-Talak. ${ }^{32}$

Menurut Ibnu al-Anbary, taqdirnya adalah sebagai berikut:

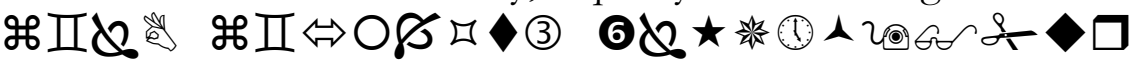
III है

○I $K \& \rightarrow \rightarrow 9 \bigotimes \rightarrow$ $202 \leftarrow \eta_{0} \hat{\text { 合}} \wedge \square \mathbb{Q}$

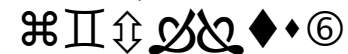
$\rightarrow \square \bullet \phi(1) \mathbf{\square} \square$ 尼

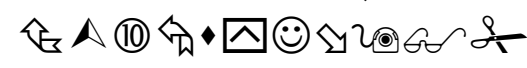
एबता $\rightarrow \square+\phi(1) \square \square$ 穴的

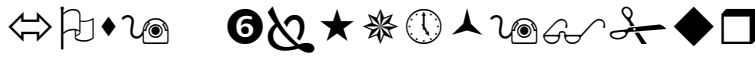

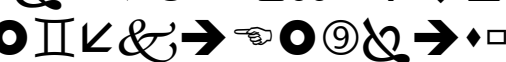
20 $2 \leftarrow \eta_{0} \hat{\text { 令}} \wedge \square \mathbb{Q}$

Dengan demikian, pengertian ayat tersebut adalah sebagai berikut: Wanita yang telah terputus dari menstruasi, iddahnya tiga bulan dan wanita yang tidak menstruasi sama sekali, iddahnya tiga bulan. 33

Menurut para ulama wanita yang telah monopouse dan wanita yang tidak haid sama sekali, iddahnya tiga bulan. Dalam masalah ini mereka tidak ada perbedaan pendapat. Namun berbeda pendapat tentang batas umur wanita yang putus dari haid tersebut. (ada yang mengatakan 60 tahun, dan ada yang mengatakan 55 tahun). ${ }^{34}$

Adapun wanita yang sebelumnya berhaid kemudian tidak haid, sedangkan umurnya masih dalam batas waktu berhaid, maka pendapat ulama sebagai berikut:

a. Hanafiyah dan Syafi'iyah berpendapat: iddah nya adalah iddah wanita berhaid (tiga quru), hingga sampai batas umur mati haid dari keluarganya yang perempuan. Apabila telah sampai batas umur mati haid, maka iddahnya di hitung dengan iddah wanita yang telah mati haid yaitu tiga bulan.

b. Malik dan Ahmad, berpendapat wanita tersebut harus menunggu 9 bulan untuk mengetahui rahimnya kosong. Setelah itu iddahnya

${ }^{32}$ Lihat, Jalal al-Din Abd al-Rahman bin Abi Bakar al-Shuyuthi, Lubab alNuzul fi asbab al-Nuzul, (Riyadh: Maktabah al-Riyadh al-Hadits, t.th), hlm. 222.

${ }^{33}$ Muhammad Ali al-Shabuny, Rawai', hlm. 611.

${ }^{34}$ Lihat Shabuny, Rawai', hlm. 611. dihitung dengan perhitungan iddah wanita yang telah mati haid yaitu tiga bulan. ${ }^{35}$

\section{Hak Wanita Yang Beriddah}

Bagi wanita yang sedang dalam iddah, mereka mempunyai hak dan juga mempunyai rambu-rambu yang tidak boleh mereka langgar. Para Ulama tidak berbeda pendapat tentang hak tempat tinggal bagi wanita yang sedang beriddah. Akan tetapi, mereka berbeda pendapat tentang wanita yang di talak dengan talak tiga. Perbedaan tersebut adalah sebagai berikut.

a. Malik dan Syafi'i, dan satu riwayat dari Ahmad, bahwa yang wajib disediakan hanya tempat tinggal. Sedangkan belanja tidak wajib diberikan

b. Abu Hanifah dan Sahabat-sahabatnya, untuk wanita yang sedang beriddah itu, wajib disediakan tempat tinggal dan wajib diberi belanja selama masa iddah

c. Ahmad dan selainnya, tidak wajib disediakan tempat tinggal dan tidak wajib diberi belanja.

Argumen yang dikemukakan oleh pendapat yang pertama (Maliki dan Syafi'i) ialah Firman Allah Q.S al-Talak ayat 6.

$\leftarrow$ เ

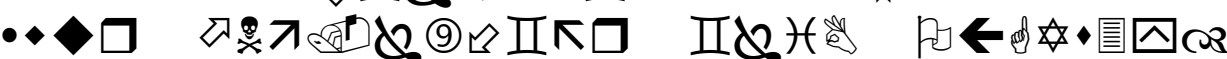

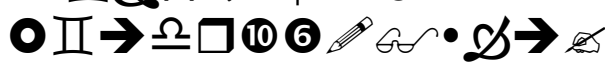

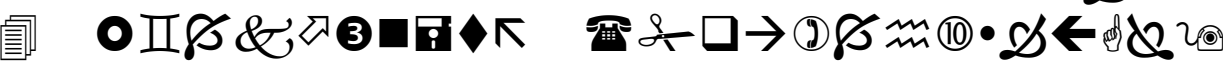

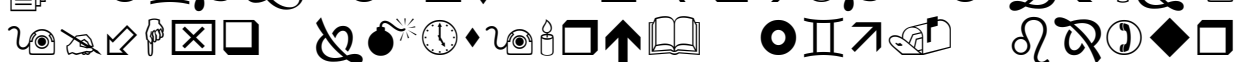

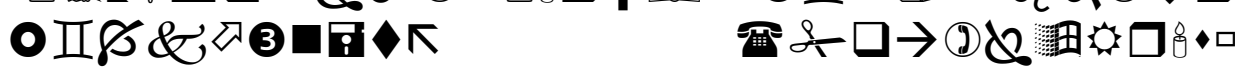

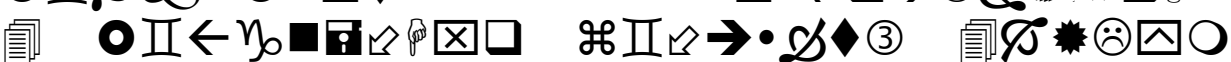

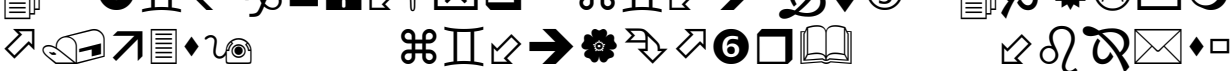

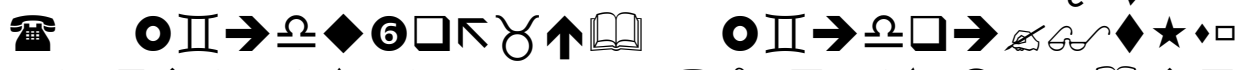

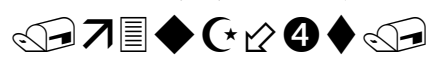
वर(ग

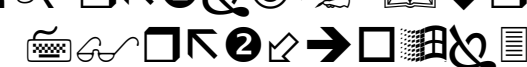

${ }^{35}$ Lihat Shabuny, Rawai', hlm. 611. 
Artinya : Tempatkanlah mereka (para isteri) di mana kamu bertempat tinggal menurut kemampuanmu dan janganlah kamu menyusahkan mereka untuk menyempitkan (hati) mereka. dan jika mereka (isteri-isteri yang sudah ditalaq) itu sedang hamil, Maka berikanlah kepada mereka nafkahnya hingga mereka bersalin, Kemudian jika mereka menyusukan (anakanak)mu untukmu Maka berikanlah kepada mereka upahnya, dan musyawarahkanlah di antara kamu (segala sesuatu) dengan baik; dan jika kamu menemui kesulitan Maka perempuan lain boleh menyusukan (anak itu) untuknya.

Menurut mereka, ketika Allah menyebutkan al-Sukna dalam ayat tersebut Allah menyebutnya secara mutlak. Artinya bagi setiap wanita yang ditalak. Akan tetapi, ketika Allah menyebut nafkah, Dia mengaitkan (qaid) dengan kehamilan. Berarti seorang wanita yang ditalak bain tidak wajib nafkah. Demikian dijelaskan oleh alShabuniy. ${ }^{36}$ Dalam kaedah ushul menyebutkan, apabila ditemukan Nash yang umum dan Nash yang ada qaidnya maka yang didahulukan adalah ayat yang ada qaid nya. ${ }^{37}$

Argument yang dikemukakan kelompok kedua adalah Firman

Allah SWT di bawah ini :

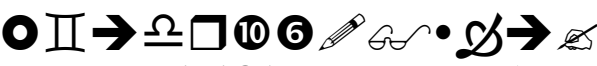

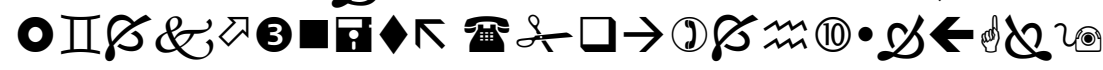

"...Dan janganlah kamu menyusahkan mereka untuk menyempitkan hati mereka..."

Tidak memberi nafkah terhadap wanita yang sedang beriddah adalah sesuatu yang sangat memberi mudharat bagi mereka. Oleh karena itu mereka mewajibkan memberi nafkah kepada wanita yang sedang beriddah. Selain itu, wanita yang beriddah wajib disediakan

\footnotetext{
36Lihat Syabuniy, hlm. 617.
}

${ }^{37}$ Lihat Abu Zaharah, hlm. 171 tempat tinggal maka wajib pula diberi nafkah. Wanita yang sedang beriddah tersebut tidak boleh keluar rumah selama mereka masih dalam iddah.

Argument yang dikemukakan oleh kelompok ketiga adalah hadis Nabi SAW sebagai berikut:

\section{لا نفقة للك و لا سكنى إنما السكنى و النفقة على من له عليه رجعة}

Hadis tersebut sebagai jawaban Nabi terhadap seorang wanita yang bertanya tentang nafkah dirinya yang telah ditalak suaminya. Dari jawaban Nabi tersebut, jelas bahwa tidak ada nafkah untuk seorang isteri yang telah ditalak tiga oleh suaminya. Nafkah hanya diwajibkan karena kemungkinan adanya istimta'. Dengan alasan, bahwa wanita yang nusyuz tidak wajib diberi nafkah. ${ }^{38}$

Bagi wanita yang ditalak suami sebelum dukbul tidak wajib iddah, akan tetapi wajib memberikan mut'ab. Mut'ah adalah sesuatu yang diberikan suami kepada isteri yang telah diceraikannya. Sebagai bentuk pertolongan, penghormatan, sebagai bukti untuk menunjukkan bahwa kesalahan bukan terdapat pada isteri yang dicerai tetapi semata-mata karena kehendak suami, untuk menutupi ketakutan terhadap talak yang dijatuhkan padanya. Sedangkan jumlahnya berdasarkan ijtihad ${ }^{39}$.

Dalam masalah mut'ah, para ulama tidak sepakat tentang wajibnya untuk semua wanita yang ditalak. Perbedaaan pendapat tersebut adalah sebagai berikut:

a. Al-Hasan al-Bashry berpendapat, mut'ah wajib bagi setiap wanita yang ditalak suaminya. Pendapat tersebut berdasarkan Q.S. al-Baqarah ayat 241:

${ }^{38}$ Lihat Syabuniy, hlm. 617.

${ }^{39}$ Menurut Malik, mut'ah tidak ada batas banyak atau sedikitnya. Menurut alSyafi'i sunat bagi suami yang kaya menyediakan pembantu (khadim) bagi suami yang sedang-sedang saja 30 dirham. Dan bagi suami yang miskin harus qana'ah (menerima apa adanya). Menurut Abu Hanifah, paling sedikit sehelai kain baju dan jilbab dan paling banyak tidak lebih setengah mahar. Ahmad, sehelai kain, sehelai baju, sekedar dapat dipakai untuk shalat, al-Shabuny jilid I, hlm. 380. 


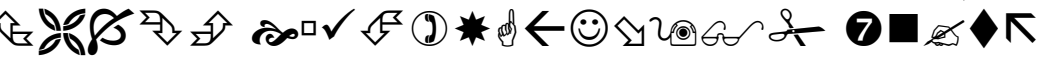

"Kepada wanita-wanita yang diceraikan (hendaklah diberikan oleh suaminya) mut'ah menurut yang ma'ruf, sebagai suatu kewajiban bagi orang-orang yang bertakwa".

b. Menurut Malik, mut'ah adalah sunat bukan wajib.

c. Menurut jumhur ulama (Hanafiyah, Syafi'iyah dan Hanabilah) hanya wajib untuk wanita-wanita yang belum disebutkan maharnya pada waktu akad nikah.

Bagi wanita yang sedang beriddah, di samping ada hak seperti yang telah disebutkan di atas, ada pula hal-hal yang dilarang. Hal-hal yang dilarang tersebut adalah sebagai berikut:

1. Al-ibdad, yaitu bersolek, memakai pakaian yang menyolok, harum-haruman, celak, inai dan lain-lain. Al-ibdad ini, selama 4 bulan 10 hari. Bagi keluarga dekat ihdad ini hanya boleh selama tiga hari.

2. Bagi wanita yang dicerai wafat suaminya boleh keluar rumah. Sebab, menurut Hanifah dan Malikiyah, wanita yang dicerai wafat suaminya tidak wajib diberi belanja. Untuk menutupi kebutuhan, wanita tersebut perlu keluar rumah. Sedangkan bagi wanita yang dicerai suaminya (tidak cerai wafat) tidak boleh keluar rumah selama iddah. ${ }^{40}$ Larangan ini bagi Hanafiyah dan Malikiyah sesuai dengan pendapat mereka di atas.

3. Wanita yang sedang dalam iddah haram menikah. Iddah tersebut mencakup iddah talak atau iddah wafat suaminya. Hal tersebut didasarkan Firman Allah Q.S. al-Baqarah: 235 sebagai berikut:

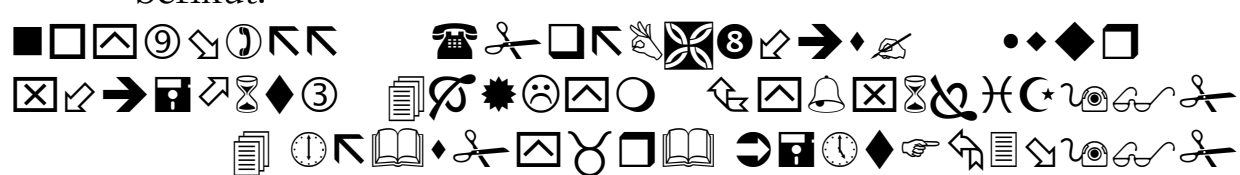

${ }^{40} \mathrm{Ibid}$, al-Munir.
“...Dan janganlah kamu ber'azam (bertetap hati) untuk berakad nikah, sebelum habis iddahnya..."

Dan para Ulama sepakat bahwa akad nikahnya fasid dan wajib difasakhkan.

\section{Hikmah Iddah}

Setiap hukum yang ditetapkan Allah SWT mengandung kemaslahatan. Kemaslahatan tersebut ada yang terjangkau oleh akal manusia dan ada yang belum terjangkau oleh pemikiran manusia. Dalam masalah iddah Allah menjelaskan dalam Firmannya adalah bertujuan untuk mengetahui suci atau tidak sucinya rahim wanita yang diceraikan agar tidak terjadi percampuran nasab. Ini sifatnya ta'abbudy (mengikut apa yang telah difirmankan Allah). Sungguhpun demikian para ulama menggali hikmah adanya iddah, sebagai berikut:

1. Untuk mengetahui sucinya rahim perempuan. Agar nasab anak jelas. Oleh sebab itu, wanita tersebut tidak boleh menyembunyikan sedikitpun tentang apa yang ada dalam rahimnya haid atau hamil.

2. Memberi kesempatan kepada sumi isteri yang bercerai untuk kembali kepada kehidupan semula jika mereka menganggap hal tersebut baik

3. Menjunjung tinggi masalah perkawinan agar dapat menghimpunkan orang-orang yang arif mengkaji masalahnya dan memberikan tempo untuk berpikir panjang untuk membina kembali rumah tangganya.

4. Kebaikan perkawinan tidak dapat terwujud sebelum suami isteri hidup lama dalam ikatan akadnya.

5. Memperhatikan/memelihara jeritan seorang wanita, memelihara keagungan kehidupan suami isteri pahit dan deritanya.

6. Agar berpikir panjang dan luas terhadap akibat perceraian; baik akibat terhadap anak atau terhadap suami dan isteri.

7. Agar suami dan isteri berpikir tentang masalah kehidupan sehingga masing-masingnya berpikir untuk memperbaiki kesalahan dan kekeliruan di masa yang akan datang. 
8. Memberi kesempatan berpikir dengan layak untuk kembali membina keluarga dengan kehidupan yang baru, yang lebih baik dari telah lalu.

Demikian dijelaskan oleh pengarang Tafsir al-Munir dalam tafsirnya. Sayid Sabiq juga menjelaskan hal yang sama dalam bukunya Figh Sunah ketika menjelaskan masalah iddah. ${ }^{41}$

\section{Kesimpulan}

Pada bagian akhir ini, penulis mengemukakan beberapa kesimpulan : Iddah wanita yang dicerai oleh suaminya (wanita tersebut tidak hamil, tidak monopouse, atau masih belum dewasa/haid, atau dewasa tapi memang tidak berhaid, atau wanita yang belum pernah di dukbul oleh suaminya), maka iddahnya tiga quru'. Wanita yang dicerai wafat suaminya iddahnya 4 bulan 10 hari, wanita yang dicerai suaminya dalam keadaan hamil maka iddahnya sampai melahirkan. Wanita-wanita yang monopouse dan wanita-wanita yang tidak berhaid iddahnya tiga bulan.

\section{Kepustakaan}

Abi al-Hasan 'Ali bin ahmad al-Wahidyn al-Naisabury, Asbab al-Nuгul, (Beirut: Daar al-Fikr, 1994).

Abi al-Husain Ahmad bin Faris bin Zakariya, Mu'jam Maqayis alLughah, (Beirut: Daar al-Fikr, t.th).

Ahmad al-Hasyimiy, Jawahir al-Balaghah fi al-Ma'any wa al-Bayan wa alBadi, (Indonesia: Maktabah Daar al-Ihya' al-Kutub alArabiyah, t.th.).

${ }^{41}$ Sayid Sabiq, hlm.141., lihat juga, al-Munir, hlm. 232.
Al-Said al-Iman Muhammad bin Ismail al-Kahlamy, Subul al-Salam, (Mesir: Syirkah Maktabah Mushthafa al-Babiy al-Halabiy wa Awladihi, 1950).

Ibnu Rusyd, Bidayatuh al-Mujtahid, (Semarang: CV. Asy Syifa’, 1990).

Jalal al-Din Abd al-Rahman bin Abi Bakar al-Suyuthi. Lubab al-Nuqul fi Asbab al-Nuzul, (Riyadh: Maktabah al-Riyadh al-Haditsah, t.th.).

Manna' al-Qaththan, Mababits fi Ulum al-Quran, (Beirut: Muassasah alRisalah, 1990).

Muhammad 'Ali al-Sayis, Tafsir Ayat al-Abkam, (tt: t.p, t.th.).

Muhammad 'Ali as-Shabuniy, Rawai'i al-Bayan: Tafsir Ayat al-Abkam min al-Quran, (Makkah al-Mukarramah: t.p., t.th).

Muhammad Abu Zahrah, Ushul al-Figh, (T.tp: Daar al-Fikr al-Arabiy, 1954).

Mukhtar Yahya dan Fatchurrahman, Dasar-Dasar Pembinaan Hukum Figh Islami, (Bandung: PT. Al-Ma'arif, 1986).

Rachmat Syafe'i, Ilmu Ushul Figih, (Bandung: CV. Pustaka Setia, 2007).

Sayyid Sabiq, Figh al-Sunah, alih bahasa oleh Mahyuddin Syaf, (Bandung Al-Ma'arif, 1996).

Umar Syihab, Al-Quran dan Kekenyalan Hukum, (Semarang: Dina Utama Semarang (DIMAS), 1993).

Wahbah al-Zuhailiy, Al-Tafsir al-Munir fi al-Aqidah wa al-Syari'ah wa alManbaj, (Beirut: Dar al-Fikr al-Mu'ashir, 1991). 